\title{
Metastatic patterns and prognosis of young lung cancer patients: a population-based study by age
}

\author{
Lan Yang ${ }^{1}$, Fang Fang ${ }^{2}$, Juan Chan ${ }^{3}$, Bojiang Chen ${ }^{1}$, Wenxin Luo ${ }^{1}$, Qing Zhu ${ }^{4}$, Dan Liu ${ }^{1}$, Weimin Li $^{1 \wedge}$ \\ ${ }^{1}$ Department of Respiratory and Critical Care Medicine, West China School of Medicine/West China Hospital, Sichuan University, Chengdu, \\ China; ${ }^{2}$ Department of Neurosurgery, West China School of Medicine/West China Hospital, Sichuan University, Chengdu, China; ${ }^{3}$ West China \\ School of Medicine, Sichuan University, Chengdu, China; ${ }^{4}$ Department of medical administration, West China School of Medicine/West China \\ Hospital, Sichuan University, Chengdu, China \\ Contributions: (I) Conception and design: D Liu, W Li; (II) Administrative support: W Li; (III) Provision of study materials or patients: L Yang, F \\ Fang, J Chan, B Chen, W Luo; (IV) Collection and assembly of data: L Yang, F Fang, J Chan, B Chen, Q Zhu; (V) Data analysis and interpretation: \\ L Yang, F Fang, B Chen, W Luo, Q Zhu; (VI) Manuscript writing: All authors; (VII) Final approval of manuscript: All authors. \\ Correspondence to: Weimin Li; Dan Liu. Department of Respiratory and Critical Care Medicine, West China School of Medicine/West China \\ Hospital, Sichuan University, Chengdu 610041, China. Email: weimin003@163.com; liudan10965@wchscu.cn.
}

\begin{abstract}
Background: We aimed to examine the different metastatic patterns and corresponding survival outcomes between all ages of young (aged $<60$ years) and elderly lung cancer patients.

Methods: Lung cancer patients from the Surveillance, Epidemiology, and End Results (SEER) database between 2010 and 2015 were divided into a young and elderly group. The young group was subdivided into four consecutive subgroups. Baseline characteristics were analyzed by the Chi-square test. Survival differences were evaluated by Kaplan-Meier curves and Cox proportional hazards models.

Results: Of the total 200,362 lung cancer patients, 155,348 were elderly patients and 45,014 were young patients, including 3,461 aged <45 years, 5,697 aged 45-49 years, 13,645 aged 50-54 years, and 22,211 aged 55-59 years. Compared with elderly lung cancer patients, extrathoracic metastases were significantly more frequent in each younger group, irrespective of the site and number of extrathoracic metastatic organs. Regardless of metastasis patterns, young ages were independent prognostic factors of lung cancerspecific survival (LCSS) [<45 years: hazard ratio (HR): 0.70; 45-49 years: HR: 0.87; 50-54 years: HR: 0.90; 55-59 years: HR: 0.93, all $\mathrm{P}$ values were <0.001]. In each age subgroup, patients with multi-organ extrathoracic metastasis had the worst LCSS.

Conclusions: Young lung cancer patients across all ages were at increased risk of extrathoracic metastasis, especially multi-organ patterns, but had a reduced risk of lung cancer-related death compared to elderly patients. Regular and meticulous monitoring of potential metastasized organs is required in young lung cancer patients throughout the follow-up period.
\end{abstract}

Keywords: Lung cancer; young; metastasis; prognosis; Surveillance, Epidemiology, and End Results (SEER)

Submitted May 12, 2021. Accepted for publication Jun 25, 2021.

doi: $10.21037 /$ atm-21-2849

View this article at: https://dx.doi.org/10.21037/atm-21-2849

^ ORCID: Lan Yang, 0000-0001-9112-4137; Dan Liu, 0000-0001-6791-1704; Weimin Li, 0000-0003-0985-0311. 


\section{Introduction}

Lung cancer is one of the leading causes of cancer morbidity worldwide, with a median age at diagnosis of 71 years (1). Previous studies assessing the metastatic patterns and prognosis of lung cancer are mainly based on elderly patients, but there are few studies examining these factors in young patients. Because of the potential interactions between metastatic patterns, prognosis, and age, a separate examination of this issue in young patients is important. Also, multiple studies have revealed that the incidence of lung cancer in young females has been on the rise in the evolution of the smoking epidemic worldwide (2), which further highlights the urgent need to assess this issue in young patients.

The definitions of age boundaries for young people vary markedly between studies on lung cancer, with the ages 35 years (3), 40 years (4), 45 years $(5,6), 50$ years $(7,8)$, and even 60 years (9) all being used. Substantial disparities has been observed in clinical features, genomic alterations and prognosis between young and old lung cancer patients (5-8). Young patients with lung cancer may represent a distinct spectrum of the disease (10).

$M$ descriptor is a strong prognostic marker for lung cancer patients (11), with a 5-year survival rate for localized stage disease of $57 \%$, and a 5 -year survival rate of only $5 \%$ for metastatic stage disease (12). Thus, a better understanding of patients who are more susceptible to metastasis and early detection of the potential metastasized organs have important implications for improving prognosis. Previous studies have revealed the extrathoracic metastatic patterns of octogenarians (9). However, the metastatic profiles of younger patients remain poorly understood and the predictions by extrapolation are challenging. Given the longer life expectancy, and the higher social and family participation of younger lung cancer patients (10), further studies are needed to characterize this subset of patients.

In this article, we conducted a population-based study in which we segregated relatively young patients (age at diagnosis less than 60 years) into four consecutive subgroups and sought to examine the relationship between different metastatic patterns and the corresponding prognostic value by age.

We present the following article in accordance with the STROBE reporting checklist (available at https://dx.doi. org/10.21037/atm-21-2849).

\section{Methods}

\section{Study population and data collection}

The study was conducted in accordance with the Declaration of Helsinki (as revised in 2013). Patients with invasive lung and bronchus cancer were identified from the Surveillance, Epidemiology, and End Results (SEER) 18-registry database between 2010 and 2015, on the basis of the International Classification of Diseases for Oncology, 3 rd edition (ICD-O-3). Informed consent was not required as there was no contact with study subjects. Any patient who met any of the following criteria were excluded: (I) patients who had a history of other malignancies, (II) patients under 18 years old at lung cancer diagnosis, (III) patients diagnosed at autopsy or death certificate only, (IV) metastatic status was not available. A total of 71,009 of the 271,371 lung cancer patients were excluded due to the exclusion criteria, resulting in 200,362 patients available for analysis. A detailed flow chart of the patient screening process is provided in Figure S1. Patients were divided into a young group and elderly group, the former of which was further subdivided into $<45,45-49,50-54$, and 55-59 age subgroups.

\section{Variable classifications}

Metastatic status was classed as non-metastasis, intrathoracic metastasis, and extrathoracic metastasis. Intrathoracic metastasis included contralateral lung tumor nodule(s) and malignant pleural (or pericardial) tumor nodules (or effusion) (13), while extrathoracic metastasis recorded in the SEER database involved bone, brain, liver, and distant lymph nodes (LNs).

We also collected baseline covariates, including sex, race, histology, grade, primary tumor site, stage at diagnosis, surgery, radiation, chemotherapy, and the follow-up records.

\section{Statistical analysis}

The baseline characteristics of the patients were summarized using descriptive statistics and compared using the Chi-square test and Fisher's exact test. Odds ratios (ORs) and corresponding 95\% confidence intervals (CIs) were determined using univariate logistic regression analyses. Kaplan-Meier curves and the log-rank test were used to compare the lung cancer-specific survival (LCSS) and overall survival (OS) between groups. Hazard ratios 
(HRs) and 95\% CIs for LCSS and OS were calculated by multivariate Cox proportional hazard models using all confounders which are listed in Table 1. Two-sided $\mathrm{P}$ values $<0.05$ were considered significant. Statistical analyses were performed using SPSS version 25 (SPSS Inc., Chicago, IL, USA) and plotted by GraphPad Prism 8.0 (GraphPad Software, La Jolla, CA, USA).

\section{Results}

\section{Patient characteristics}

A total of 200,362 lung cancer patients were ultimately included in this study, comprising 45,014 younger and 155,348 elderly patients. We further categorized young patients into four consecutive subgroups: $<45$ years $(\mathrm{n}=3,461), 45-49$ years $(\mathrm{n}=5,697), 50-54$ years $(\mathrm{n}=13,645)$, and 55-59 years $(n=22,211)$. The detailed baseline characteristics of included patients by age groups are described in Table 1. The youngest group ( $<45$ years) included more females than males ( $52 \%$ vs. $48 \%$ ), while all other age groups included more males than females. Adenocarcinoma was the dominant histological subtype across each age group, particularly in the youngest group. The proportion of squamous cell carcinoma had a significant positive association with age $(9.3 \%, 13.5 \%$, $15.8 \%, 18.5 \%$, and $24.8 \%$ in aged $<45,45-49,50-54$, $55-59$, and $\geq 60$ years, respectively). With aging, there was a decreasing trend in the proportion of advanced lung cancer patients, but the proportion of patients undergoing treatment, including surgery, radiation, and chemotherapy, progressively declined.

\section{Metastatic patterns}

Irrespective of the metastasis sites, extrathoracic metastasis was significantly more frequent in each younger group than in elderly patients, whereas intrathoracic metastasis showed contrasting trends. Among extrathoracic metastasis, bone was the most common organ of metastasis, with the highest occurrences in patients aged $<45$ years $(24.4 \%)$. Similar tendencies were obtained in distant LN metastasis and multi-extrathoracic metastasis. The incidence rate of brain metastasis was highest in patients aged $50-54$ years $(20.1 \%)$, and the incidence rate of liver metastasis was highest in patients aged $55-59$ years (13.7\%) (Figure 1). Further univariate logistic regression analyses were concordant with these results. Compared with elderly patients, younger patients tended to have less intrathoracic metastasis. The highest ORs of bone metastasis, and multi-extrathoracic metastasis were all observed in patients aged $<45$ years. Lung cancer patients aged 50-54 and 55-59 years were more likely to have brain metastasis (OR: 2.00, 95\% CI: 1.91-2.09, $\mathrm{P}<0.001$ ) and liver metastasis (OR: 1.22, 95\% CI: 1.17-1.28, $\mathrm{P}<0.001$ ), respectively (Figure S2).

\section{Combination of metastases}

All young groups had a higher proportion of patients with metastasis than elderly group $56.7 \%$ in $<45$ years, $59.4 \%$ in $45-49$ years, $57.8 \%$ in $50-54$ years, and $55.9 \%$ in $55-59$ years vs. $50.2 \%$ in the elderly group) (Table S1). Among the cohort of metastatic patients, the majority of patients had extrathoracic metastasis (Table S1). Bone metastasis was the most common single-organ metastasis in the elderly group $(18.1 \%)$, whereas brain metastasis was the leading single-organ metastasis in each younger group ( $16.6 \%$ in patients aged $<45$ years, $17.4 \%$ in $45-49$ years, $18.8 \%$ in $50-54$ years, $16.4 \%$ in $55-59$ years). For multiorgan metastases, the bi-organ patterns (aged $<45$ years: $22.9 \%$, aged $45-49$ years: $20.0 \%$, aged $50-54$ years: $21.1 \%$, aged $55-59$ years: $21.7 \%$, and aged $\geq 60$ years: $16.9 \%$ ) were significantly more common than tri-organ patterns (aged $<45$ years: $7.7 \%$, aged $45-49$ years: $6.9 \%$, aged $50-54$ years: $6.3 \%$, aged $55-59$ years: $6.6 \%$, and aged $\geq 60$ years: $4.4 \%$ ) and tetra-organ patterns (aged $<45$ years: $1.0 \%$, aged $45-49$ years: $1.0 \%$, aged $50-54$ years: $0.8 \%$, aged $55-59$ years: $0.9 \%$, and aged $\geq 60$ years: $0.5 \%$ ) (Figure $S 3$ ).

Further analysis revealed that for bi-organ patterns, bone and brain metastases were the most common metastases in the youngest group (4.6\%) and the second youngest group $(3.7 \%)$. Bone and liver metastasis were more frequent in the other three groups (aged $<45$ years: $3.6 \%$, aged $50-54$ years: $3.7 \%$, and aged $55-59$ years: $4.2 \%$ ). For tri-organ patterns, the bone, brain, and liver metastasis pattern was the most common combination in all age groups (aged $<45$ years: $2.3 \%$, aged $45-49$ years: $1.8 \%$, aged $50-54$ years: $1.8 \%$, aged $55-59$ years: $1.7 \%$, and aged $\geq 60$ years: $1.1 \%$ ) (Table 2 ).

\section{Patient survival across age groups}

As age increased, there was a significant decrease in the median LCSS (mLCSS) of lung cancer patients (Table 2, Figure $2 A$ ). The youngest group had the best mLCSS of 25.0 months, with 1-, 2-, 3-, and 5-year LCSS rates 
Table 1 Baseline characteristics of LC patients stratified by age

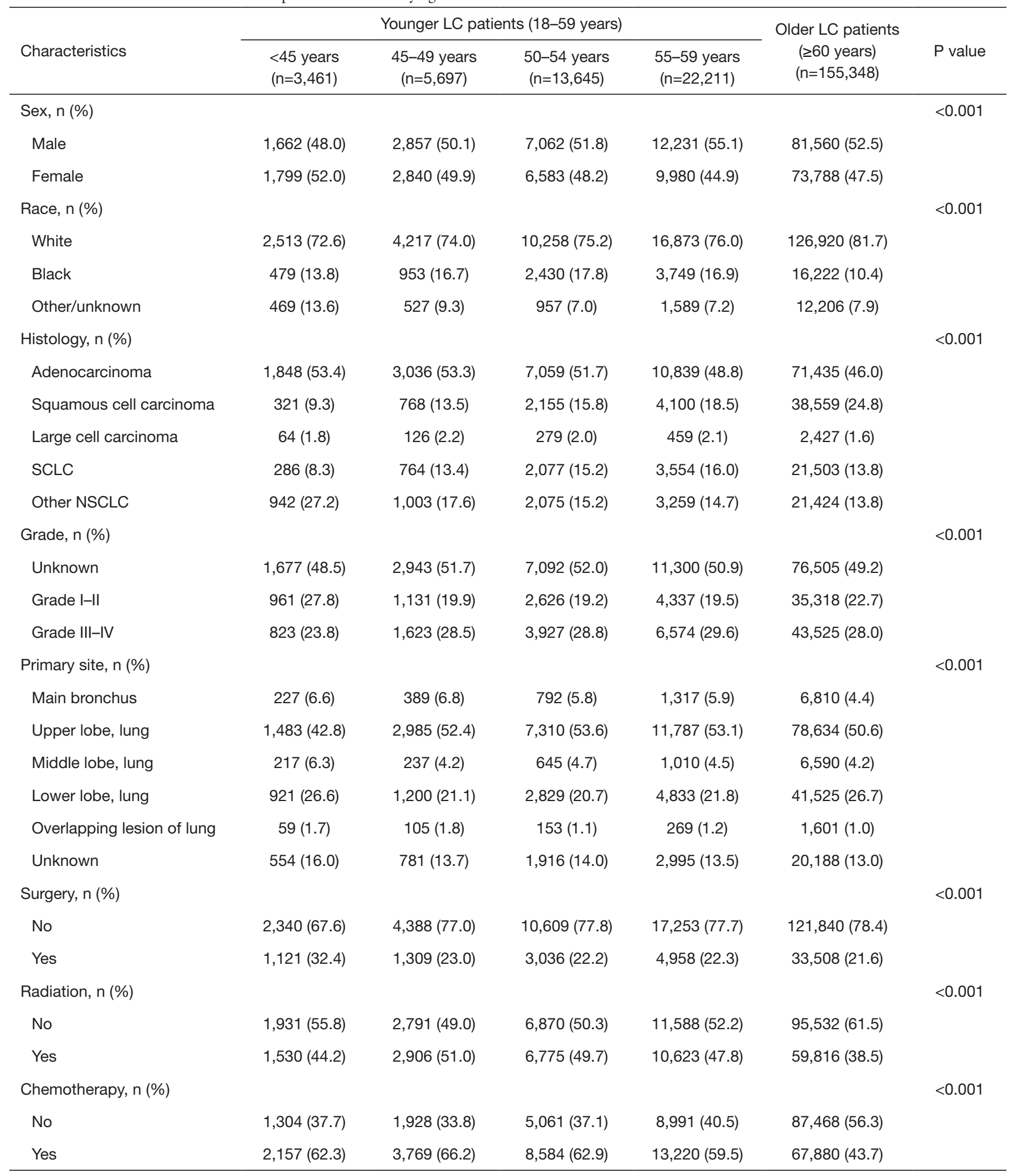

Table 1 (continued) 
Table 1 (continued)

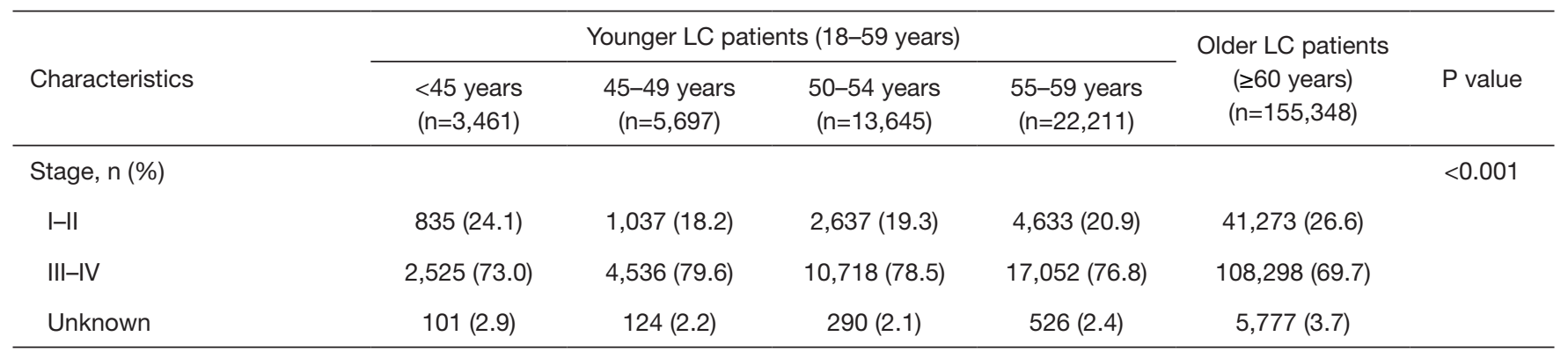

LC, lung cancer; SCLC, small cell lung cancer; NSCLC, non-small cell lung cancer.

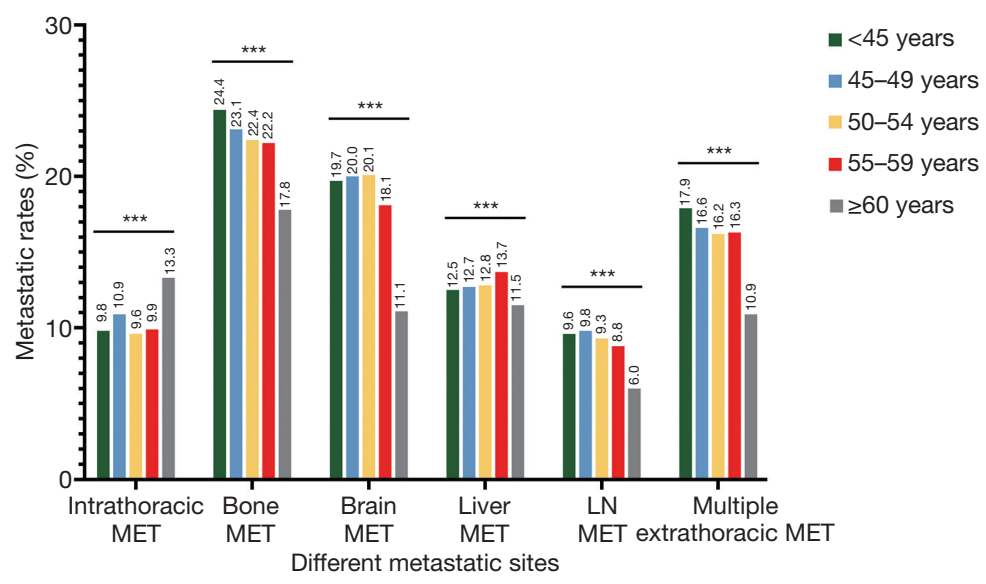

Figure 1 Comparison of the frequencies of different sites in different age groups. ${ }^{* *}, \mathrm{P}<0.001$. MET, metastases; LN, lymph node.

of $64.7 \%, 50.0 \%, 43.1 \%$, and $37.0 \%$, respectively. The worst prognosis was observed in the oldest group, with a mLCSS of 12.0 months and 1-, 2-, 3-, and 5-year LCSS rates of $48.3 \%, 35.3 \%, 29.2 \%$, and $23.2 \%$, respectively (Table 2). Similar trends were observed in the corresponding OS (Table 2). Multivariate analysis demonstrated that ages younger than 60 years were independent prognostic factors for LCSS (aged $<45$ years: HR: $0.70, \mathrm{P}<0.001$; aged 45-49 years: HR: $0.87, \mathrm{P}<0.001$; aged $50-54$ years: HR: $0.90, \mathrm{P}<0.001$; aged $55-59$ years: HR: $0.93, \mathrm{P}<0.001$ ) (Table 3) and OS (aged $<45$ years: HR: $0.67, \mathrm{P}<0.001$; aged $45-49$ years: HR: $0.84, \mathrm{P}<0.001$; aged $50-54$ years: HR: $0.86, \mathrm{P}<0.001$; aged $55-59$ years: HR: $0.91, \mathrm{P}<0.001$ ) (Table S2). We further assessed the LCSS disparity of lung cancer patients with and without metastasis stratified by age. Irrespective of metastasis patterns, significant differences were observed in the median survival for lung cancer patients across age groups $(\mathrm{P}<0.001)$ (Figure $2 B, C, D, E, F, G, H)$.

\section{Correlation of different metastasis patterns with survival}

We compared the effects of metastasis patterns on the survival of lung cancer patients in each age group. Patients without metastasis had the best mLCSS, followed by patients with intrathoracic metastasis, then singleorgan extrathoracic metastasis, and finally multi-organ extrathoracic metastasis $(\mathrm{P}<0.001)$, both in all patients (Figure $3 A$ ) and in each age subgroup (Figure $3 B, C, D, E, F$ ). In the Cox regression analysis of different extrathoracic sites, liver metastasis was most strongly associated with worse survival in all subgroups (aged $<45$ years: HR: 6.98, $\mathrm{P}<0.001$; aged 45-49 years: HR: 5.64, $\mathrm{P}<0.001$; aged 50-54 years: HR: 5.60, $\mathrm{P}<0.001$; aged $55-59$ years: HR: 5.83, $\mathrm{P}<0.001$; aged $\geq 60$ years: HR: $5.33, \mathrm{P}<0.001)$ (Figure S4). The Kaplan-Meier survival curves for all patients by the metastatic organs indicated that there was a statistical difference $(\mathrm{P}<0.001)$ (Figure $\mathrm{S} 5 \mathrm{~A})$. The same significant differences were found regardless of age 
Table 2 Kaplan-Meier survival analysis in lung cancer patients across age groups

\begin{tabular}{|c|c|c|c|c|c|c|}
\hline Survival status & $\begin{array}{l}<45 \text { years } \\
(n=3,461)\end{array}$ & $\begin{array}{c}45-49 \text { years } \\
(n=5,697)\end{array}$ & $\begin{array}{c}50-54 \text { years } \\
(n=13,645)\end{array}$ & $\begin{array}{c}55-59 \text { years } \\
(n=22,211)\end{array}$ & $\begin{array}{l}\geq 60 \text { years } \\
(n=77,944)\end{array}$ & $P$ value \\
\hline \multicolumn{7}{|c|}{ Median survival time (months) } \\
\hline mLCSS & $25.0(22.7,27.3)$ & $15.0(14.2,15.8)$ & $14.0(13.5,13.4)$ & $13.0(12.7,13.4)$ & $12.0(11.9,12.1)$ & $<0.001$ \\
\hline mOS & $22.0(20.2,23.8)$ & $13.0(12.3,13.7)$ & $13.0(12.6,13.4)$ & $12.0(11.7,12.3)$ & $10.0(9.9,10.1)$ & $<0.001$ \\
\hline LCSS & $64.7(63.1,66.3)$ & $54.2(52.8,55.6)$ & $52.9(52.1,53.7)$ & $51.2(50.6,51.8)$ & $48.3(48.1,48.5)$ & - \\
\hline OS & $62.9(61.3,64.5)$ & $52.2(50.8,53.6)$ & $50.7(49.9,51.5)$ & $48.5(47.9,49.1)$ & $44.5(44.3,44.7)$ & - \\
\hline \multicolumn{7}{|l|}{ 2-year (\%) } \\
\hline LCSS & $50.0(48.2,51.8)$ & $38.0(36.6,39.4)$ & $37.2(36.4,38.0)$ & $36.4(35.8,37.0)$ & $35.3(35.1,35.5)$ & - \\
\hline OS & $40.5(38.7,42.3)$ & $28.8(27.6,30.0)$ & $27.8(27.0,28.6)$ & $26.6(26.0,27.2)$ & $24.2(24.0,24.4)$ & - \\
\hline \multicolumn{7}{|l|}{ 5-year (\%) } \\
\hline LCSS & $37.0(35.0,39.0)$ & $25.4(24.0,26.8)$ & $24.8(23.8,25.8)$ & $24.2(23.4,25.0)$ & $23.2(23.0,23.4)$ & - \\
\hline OS & $33.8(31.8,35.8)$ & $22.9(21.5,24.3)$ & $21.8(21.0,22.6)$ & $20.5(19.9,21.1)$ & $17.4(17.2,17.6)$ & - \\
\hline
\end{tabular}

LCSS, lung cancer-specific survival; OS, overall survival; mLCSS, median LCSS; mOS, median OS.

(Figure S5B,C,D,E,F).

\section{Discussion}

In this large retrospective population-based study, we performed, for the first time, consecutive age groupstratified analysis to investigate the different metastatic patterns among patients with lung cancer between age groups. We demonstrated that compared with elderly lung cancer patients, young patients of all ages were more likely to have more extrathoracic metastasis, both in terms of site and number of extrathoracic metastatic organs.

These findings may be attributed to the following reasons. Firstly, both the relatively low screening attendance (14-17) and the asymptomatic nature at the early stages of lung cancer currently make early diagnosis considerably more difficult for young patients. Secondly, clinical misdiagnosis, according to the low incidence of lung cancer in young patients, may further delay the cancer diagnosis of this subset of patients (6). Finally, lung cancer with earlier disease onset may present a distinct disease entity with more aggressive disease biology $(8,18)$. As such, Li et al. recommend that age 45 may be the optimal screening cut- off for initiating lung cancer screening (19), with the aim of earlier detection and treatment of young lung cancer patients.

In terms of the relationship between metastasis organs and different ages, previous studies have suggested that as two of the major extrathoracic lesions, bone and brain metastasis tend to occur in patients less than 60 years compared to patients greater than 60 years $(20,21)$. Consistent with these findings, based on age-stratified analysis, we further revealed that bone metastasis was the most common lesion in patients of all ages, particularly in patients younger than 45 years, while brain metastasis was most commonly observed in patients aged $50-54$ years. Since small-cell lung cancer (SCLC) tends to have liver metastasis (22), the highest incidence of liver metastasis in patients aged 55-59 years may be ascribed to the larger proportion of SCLC in this age group. In lung cancer patients across ages, single-organ metastasis was far more frequent than bi-organ, tri-organ, and tetra-organ metastasis. Similar patterns were also reported in pancreatic cancer (23), breast cancer (24), and extrahepatic bile duct cancer (25).

In this study, younger age was associated with roughly 

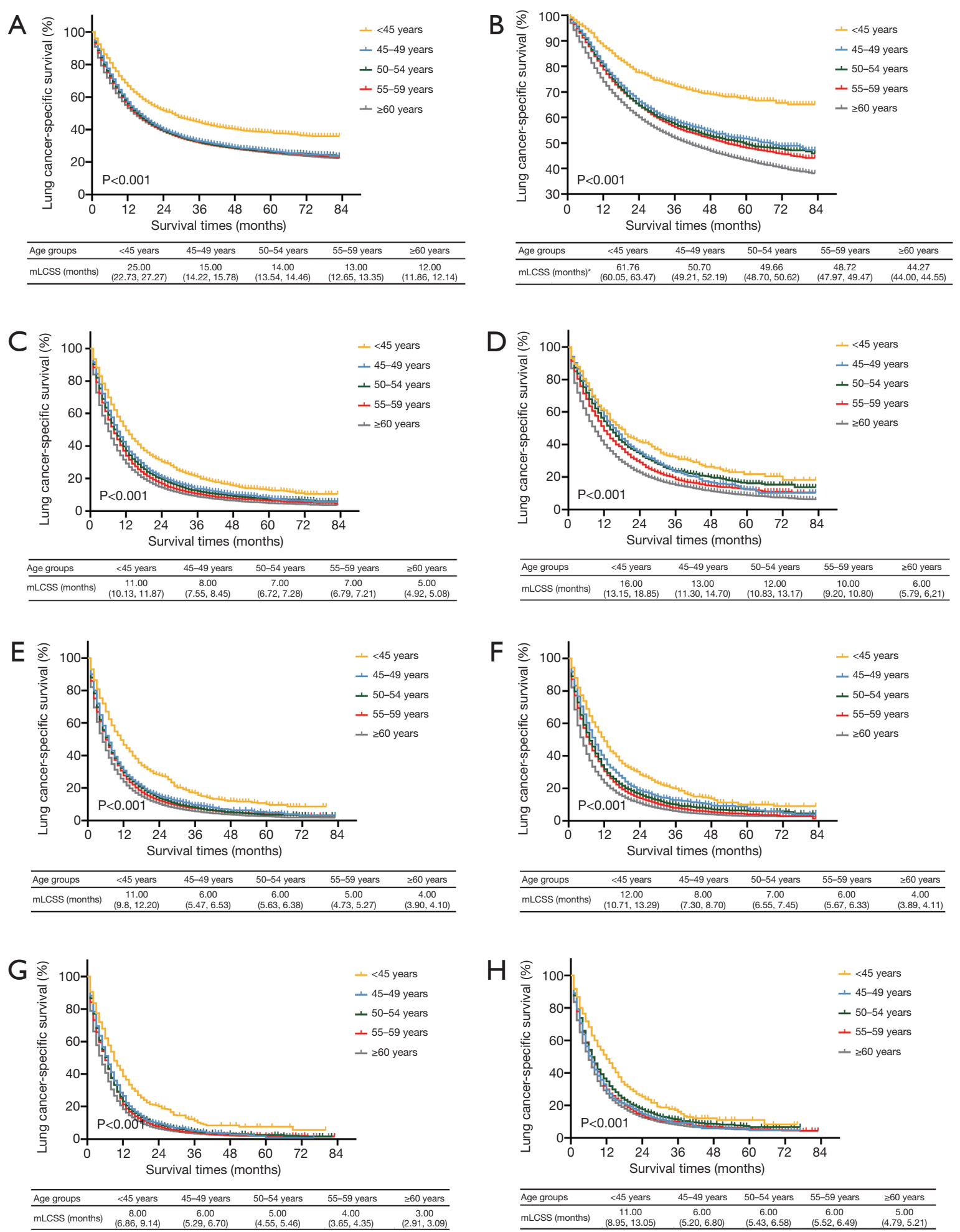

Figure 2 Comparison of Kaplan-Meier LCSS curves for patients across age groups. Kaplan-Meier plots for (A) all lung cancer patients, (B) patients without metastasis, (C) patients with metastasis, (D) patients with intrathoracic metastasis, (E) patients with bone metastasis, (F) patients with brain metastasis, $(\mathrm{G})$ patients with liver metastasis, $(\mathrm{H})$ patients with distant LNs metastasis. * , the median survival time of patients aged $<45$ years was not reached. LCSS, lung cancer-specific survival; mLCSS, median LCSS; LN, lymph node. 
Table 3 Multivariate analysis of LCSS of lung cancer patients

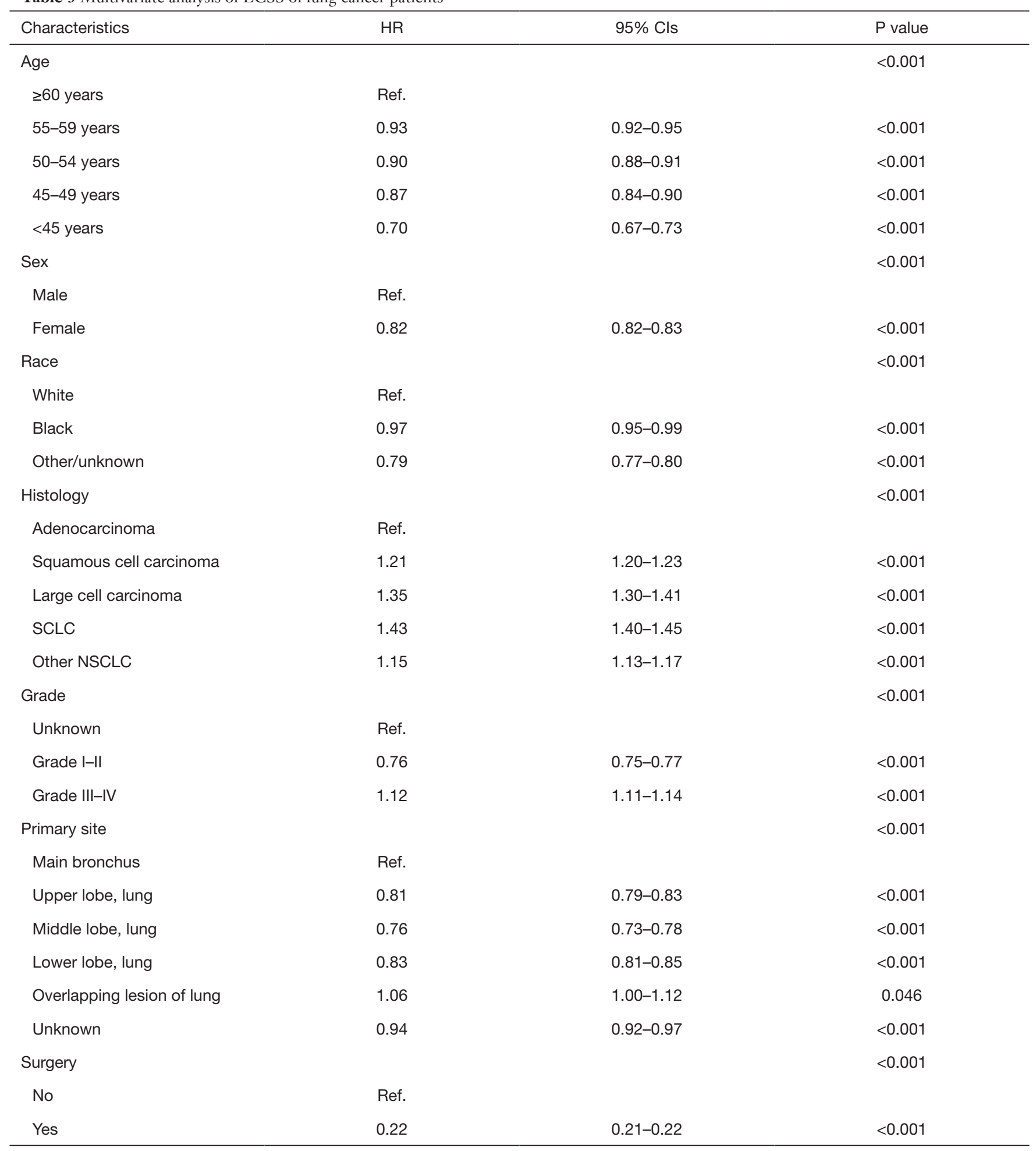

Table 3 (continued) 
Table 3 (continued)

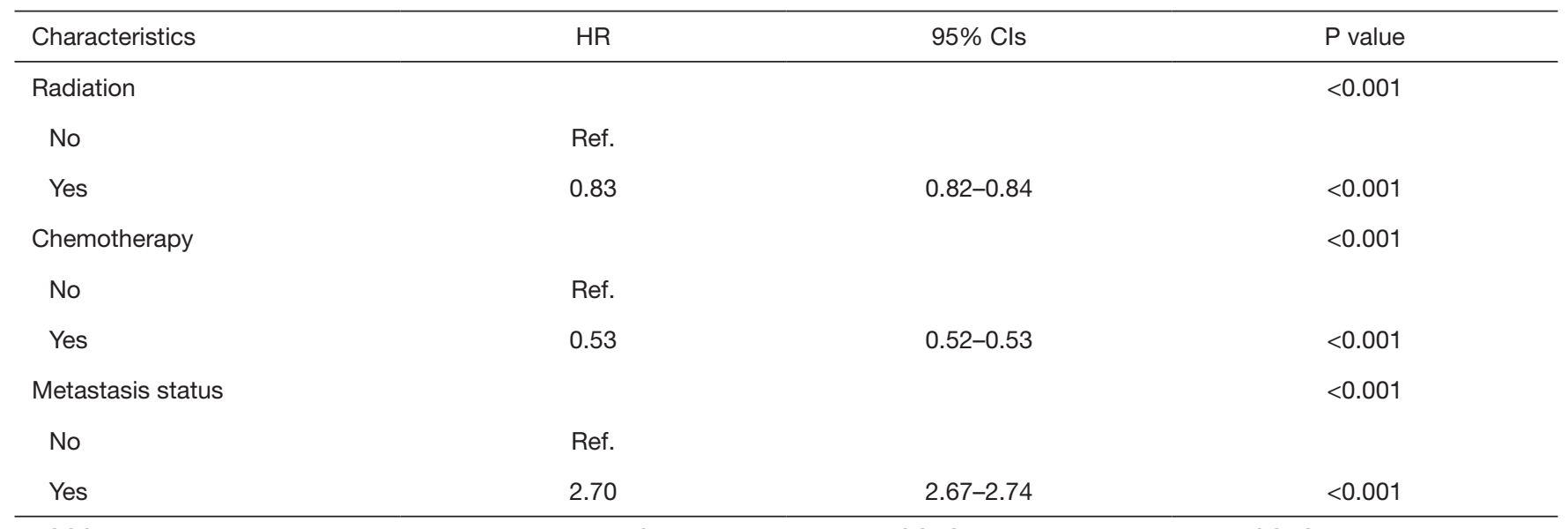

LCSS, lung cancer-specific survival; HR, hazard ratio; Cl, confidence interval; SCLC, small cell lung cancer; NSCLC, non-small cell lung cancer.
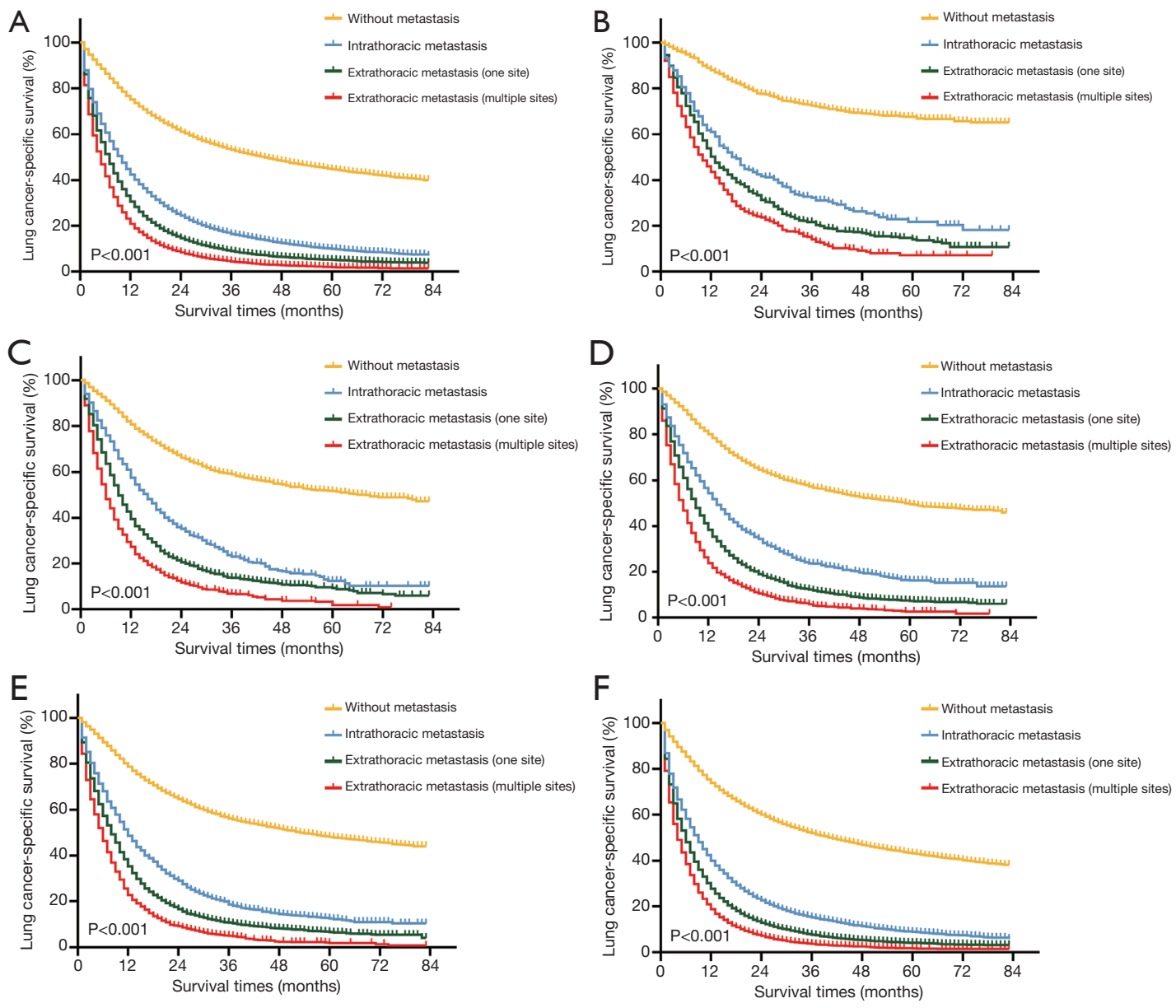

Figure 3 Kaplan-Meier LCSS curves of lung cancer patients at different ages stratified by different metastasis patterns. (A) All lung cancer patients; (B) patients aged <45 years; (C) patients aged 45-49 years; (D) patients aged 50-54 years; (E) patients aged 55-59 years; (F) patients $\geq 60$ years. LCSS, lung cancer-specific survival. 
increasing trends of LCSS and OS, regardless of the metastasis patterns. Although young patients of all ages presented with extensive disease more often, multivariate analysis confirmed that younger ages were significant positive predictors of LCSS and OS. This finding could be in large part due to the different percentages of lung cancer patients who received treatments across age groups. Sacher et al. emphasized that the younger the age at diagnosis, the more patients harboring a targetable genotype (8). Therefore, besides surgery, radiation, and chemotherapy, the emergence of targeted therapy may widen the survival gap between age groups. Further survival analyses stratified by age revealed that in all age groups, the most significant survival advantage was in non-metastatic lung cancer patients, worse survival was in intrathoracic metastasis and single-organ extrathoracic metastasis, and the poorest survival was in multi-organ extrathoracic metastasis. In view of the higher incidence of multi-organ extrathoracic metastasis in young patients, regular imaging of distant organs including bone, brain, and liver among others requires closer attention throughout the follow-up period.

Several limitations should be mentioned. Firstly, although population-based data were used, this present study is a retrospective analysis. Given that detailed metastasis statuses were collected in 2010 in the SEER database, we used 2010 as the starting year to enroll patients. Secondly, for metastatic lesions, only intrathoracic, bone, brain, liver, and distant LN metastasis are recorded in the SEER database. The current results confirmed that metastasis which occurred in other organs accounted for approximately $7.3 \%$ to $8.1 \%$ in the metastasis for lung cancer patients of different ages, such as the adrenal gland (26). Finally, the exact numbers of metastatic lesions in different organs were not available in the SEER database. Therefore, we could not further categorize patients with single-organ metastasis into M1b (single lesion) and M1c (multiple lesions) on the basis of the eighth edition of TNM classification (11).

In conclusion, we found that compared to elderly patients, young patients across all ages were at increased risk of extrathoracic metastasis, especially multi-organ metastasis, but manifested a reduced risk of lung cancerrelated death. Young lung cancer patients of different ages exhibited different clinicopathological features and metastatic patterns, together with survival disparities. Considering the more favorable outcome and longer potential years of life saved, more meticulous long-term monitoring of potential metastasis organs are required in young lung cancer patients.

\section{Acknowledgments}

Funding: This research was funded by the National Natural Science Foundation of China, grant number 81871890 and 91859203; National Guided Science and Technology Development Project of Sichuan Province (No. 2020ZYD009).

\section{Footnote}

Reporting Checklist: The authors have completed the STROBE reporting checklist. Available at https://dx.doi. org/10.21037/atm-21-2849

Conflicts of Interest: All authors have completed the ICMJE uniform disclosure form (available at https://dx.doi. org/10.21037/atm-21-2849). The authors have no conflicts of interest to declare.

Ethical Statement: The authors are accountable for all aspects of the work in ensuring that questions related to the accuracy or integrity of any part of the work are appropriately investigated and resolved. The study was conducted in accordance with the Declaration of Helsinki (as revised in 2013).

Open Access Statement: This is an Open Access article distributed in accordance with the Creative Commons Attribution-NonCommercial-NoDerivs 4.0 International License (CC BY-NC-ND 4.0), which permits the noncommercial replication and distribution of the article with the strict proviso that no changes or edits are made and the original work is properly cited (including links to both the formal publication through the relevant DOI and the license). See: https://creativecommons.org/licenses/by-nc-nd/4.0/.

\section{References}

1. 1. Howlader N, Noone AM, Krapcho M, et al. editors. SEER Cancer Statistics Review, 1975-2017. Bethesda: National Cancer Institute, 2020.

2. Jemal A, Miller KD, Ma J, et al. Higher lung cancer incidence in young women than young men in the United States. N Engl J Med 2018;378:1999-2009.

3. Liu B, Quan X, Xu C, et al. Lung cancer in young adults 
aged 35 years or younger: a full-scale analysis and review. J Cancer 2019;10:3553-9.

4. Fidler MM, Reulen RC, Bright CJ, et al. Respiratory mortality of childhood, adolescent and young adult cancer survivors. Thorax 2018;73:959-68.

5. Luo W, Tian P, Wang Y, et al. Characteristics of genomic alterations of lung adenocarcinoma in young neversmokers. Int J Cancer 2018;143:1696-705.

6. Xia J, Li H, Ji Y, et al. Clinicopathologic characteristics and EGFR mutations in lung cancer patients aged below 45 years. Curr Probl Cancer 2019;43:363-70.

7. Yoneyama R, Saji H, Kato Y, et al. Clinicopathological characteristics and treatment strategies for young lung cancer patients. Ann Transl Med 2019;7:100.

8. Sacher AG, Dahlberg SE, Heng J, et al. Association between younger age and targetable genomic alterations and prognosis in non-small-cell lung cancer. JAMA Oncol 2016;2:313-20.

9. Gu Y, Zhang J, Zhou Z, et al. Metastasis patterns and prognosis of octogenarians with NSCLC: a populationbased study. Aging Dis 2020;11:82-92.

10. Cullivan S, Ni Mhaolcatha S, Henry MT, et al. Lung cancer in young patients: tumour characteristics and treatment in an Irish population. Transl Cancer Res 2019;8:1109-15.

11. Liu S, Zhou F, Liu Z, et al. Predictive and prognostic significance of $M$ descriptors of the 8th TNM classification for advanced NSCLC patients treated with immune checkpoint inhibitors. Transl Lung Cancer Res 2020;9:1053-66.

12. Siegel RL, Miller KD, Jemal A. Cancer statistics, 2020. CA Cancer J Clin 2020;70:7-30.

13. Goldstraw P, Crowley J, Chansky K, et al. The IASLC Lung Cancer Staging Project: proposals for the revision of the TNM stage groupings in the forthcoming (seventh) edition of the TNM Classification of malignant tumours. J Thorac Oncol 2007;2:706-14. Erratum in: J Thorac Oncol 2007;2:985.

14. Moyer VA; U.S. Preventive Services Task Force. Screening for lung cancer: U.S. Preventive Services Task Force recommendation statement. Ann Intern Med 2014;160:330-8.

15. Field JK, Smith RA, Aberle DR, et al. International Association for the Study of Lung Cancer Computed Tomography Screening Workshop 2011 report. J Thorac Oncol 2012;7:10-9.

16. Jaklitsch MT, Jacobson FL, Austin JH, et al. The American
Association for Thoracic Surgery guidelines for lung cancer screening using low-dose computed tomography scans for lung cancer survivors and other high-risk groups. J Thorac Cardiovasc Surg 2012;144:33-8.

17. Shankar A, Saini D, Dubey A, et al. Feasibility of lung cancer screening in developing countries: challenges, opportunities and way forward. Transl Lung Cancer Res 2019;8:S106-21.

18. Viñal D, Martínez D, Higuera O, et al. Genomic profiling in non-small-cell lung cancer in young patients. A systematic review. ESMO Open 2021;6:100045.

19. Li C, Liang $\mathrm{H}$, Zhong $\mathrm{N}$, et al. Optimal starting age for lung cancer screening with low-dose computed tomography: a population level analysis. J Thorac Oncol 2019;14:e82-4.

20. Liu $\mathrm{W}, \mathrm{Wu} \mathrm{J}$. Lung cancer with bone metastases in the United States: an analysis from the Surveillance, Epidemiologic, and End Results database. Clin Exp Metastasis 2018;35:753-61.

21. Goncalves PH, Peterson SL, Vigneau FD, et al. Risk of brain metastases in patients with nonmetastatic lung cancer: Analysis of the Metropolitan Detroit Surveillance, Epidemiology, and End Results (SEER) data. Cancer 2016;122:1921-7.

22. Wang X, Wang Z, Pan J, et al. Patterns of extrathoracic metastases in different histological types of lung cancer. Front Oncol 2020;10:715.

23. Fan Y, Lesina M, Algül H. Subtypes of pancreatic stellate cells and distant metastasis of pancreatic ductal adenocarcinoma. Ann Transl Med 2020;8:671.

24. Wang Z, Wang H, Ding X, et al. A large-cohort retrospective study of metastatic patterns and prognostic outcomes between inflammatory and noninflammatory breast cancer. Ther Adv Med Oncol 2020;12:1758835920932674.

25. Wang X, Yu GY, Chen M, et al. Pattern of distant metastases in primary extrahepatic bile-duct cancer: A SEER-based study. Cancer Med 2018;7:5006-14.

26. Riihimäki M, Hemminki A, Fallah $M$, et al. Metastatic sites and survival in lung cancer. Lung Cancer 2014;86:78-84.

Cite this article as: Yang L, Fang F, Chan J, Chen B, Luo W, Zhu Q, Liu D, Li W. Metastatic patterns and prognosis of young lung cancer patients: a population-based study by age. Ann Transl Med 2021;9(14):1159. doi: 10.21037/atm-21-2849 


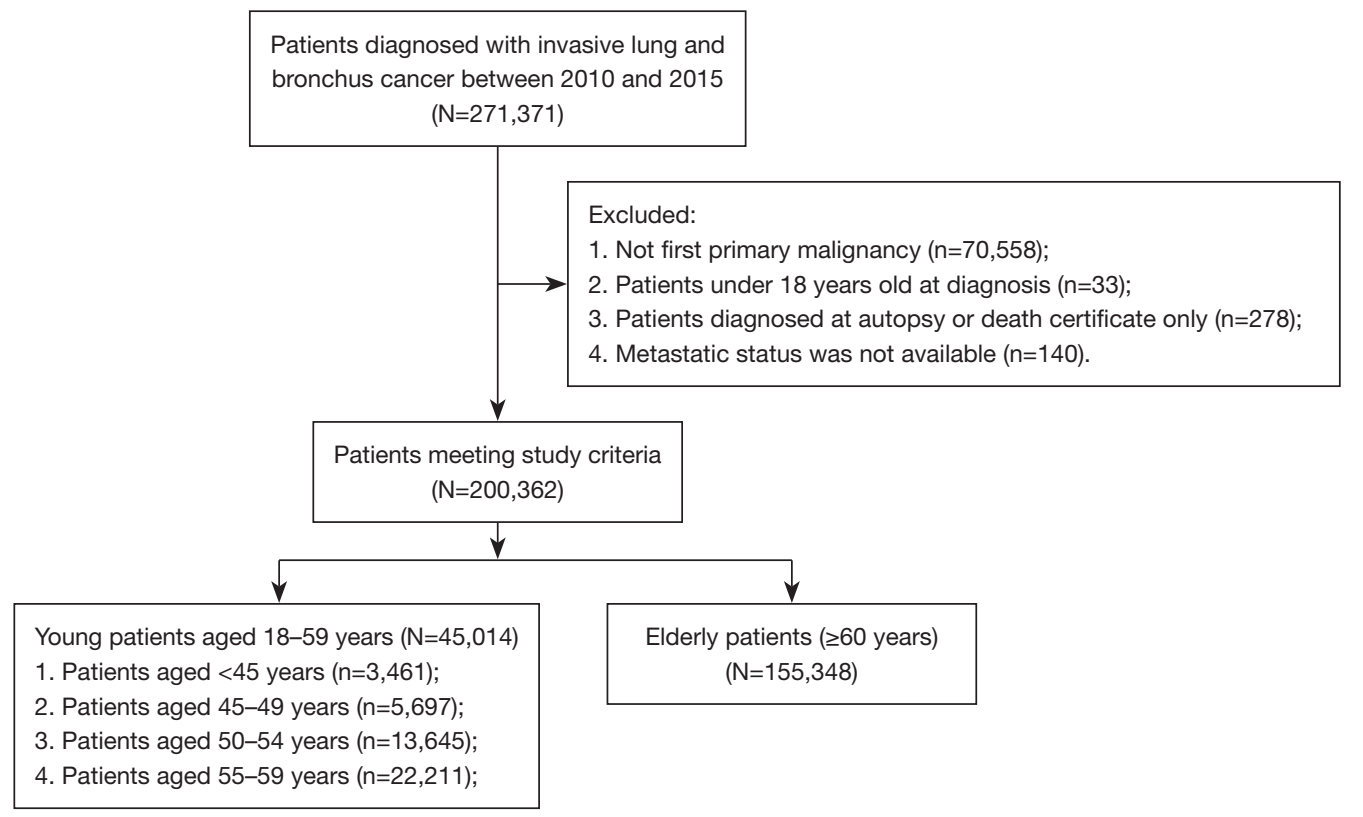

Figure S1 Flowchart of the patient selection process in this study.

\begin{tabular}{|c|c|c|c|c|c|}
\hline Metastatic site & Variables & Forest Plot & & Odds Ratio $(95 \% \mathrm{Cl})$ & P-value \\
\hline \multirow[t]{5}{*}{ Intrathoracic metastase } & $\geqslant 60$ years & & & Ref & \\
\hline & $<45$ years & $\longmapsto$ & & $0.71(0.63-0.79)$ & $<0.001$ \\
\hline & $45-49$ years & $\mapsto$ & & $0.80(0.73-0.87)$ & $<0.001$ \\
\hline & $50-54$ years & nor & & $0.69(0.65-0.73)$ & $<0.001$ \\
\hline & $55-59$ years & - & & $0.72(0.69-0.75)$ & $<0.001$ \\
\hline \multirow[t]{5}{*}{ Bone metastasis } & $\geqslant 60$ years & & & Ref & \\
\hline & $<45$ years & & $\longmapsto$ & $1.49(1.37-1.61)$ & $<0.001$ \\
\hline & $45-49$ years & & $\mapsto$ & $1.38(1.30-1.47)$ & $<0.001$ \\
\hline & $50-54$ years & & $\mapsto-1$ & $1.33(1.27-1.39)$ & $<0.001$ \\
\hline & $55-59$ years & & $\mapsto-1$ & $1.32(1.27-1.36)$ & $<0.001$ \\
\hline \multirow[t]{5}{*}{ Brain metastasis } & $\geqslant 60$ years & & & Ref & \\
\hline & $<45$ years & & $\longmapsto$ & $1.96(1.80-2.13)$ & $<0.001$ \\
\hline & $45-49$ years & & $\longmapsto$ & $1.99(1.86-2.13)$ & $<0.001$ \\
\hline & $50-54$ years & & $\longmapsto$ & $2.00(1.91-2.09)$ & $<0.001$ \\
\hline & $55-59$ years & & $\mapsto$ & $1.76(1.70-1.83)$ & $<0.001$ \\
\hline \multirow[t]{5}{*}{ Liver metastasis } & $\geqslant 60$ years & & & Ref & \\
\hline & $<45$ years & & 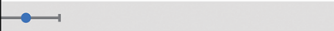 & $1.09(0.99-1.21)$ & 0.088 \\
\hline & $45-49$ years & & $\longmapsto$ & $1.12(1.04-1.21)$ & 0.005 \\
\hline & $50-54$ years & & $\mapsto-1$ & $1.13(1.07-1.19)$ & $<0.001$ \\
\hline & $55-59$ years & & tor & $1.22(1.17-1.28)$ & $<0.001$ \\
\hline \multirow[t]{5}{*}{ Distant LN metastasis } & $\geqslant 60$ years & & & Ref & \\
\hline & $<45$ years & & $\longmapsto$ & $1.66(1.48-1.86)$ & $<0.001$ \\
\hline & $45-49$ years & & $\longmapsto$ & $1.69(1.55-1.85)$ & $<0.001$ \\
\hline & $50-54$ years & & $\longmapsto$ & $1.59(1.50-1.69)$ & $<0.001$ \\
\hline & $55-59$ years & & $\longmapsto$ & $1.51(1.44-1.59)$ & $<0.001$ \\
\hline \multirow[t]{5}{*}{ Multiple extrathoracic metastase } & $\geqslant 60$ years & & & Ref & \\
\hline & $<45$ years & & $\longmapsto$ & $1.77(1.62-1.94)$ & $<0.001$ \\
\hline & $45-49$ years & & $\longmapsto$ & $1.62(1.51-1.74)$ & $<0.001$ \\
\hline & $50-54$ years & & $\mapsto$ & $1.58(1.51-1.66)$ & $<0.001$ \\
\hline & $55-59$ years & & $\mapsto-1$ & $1.59(1.53-1.65)$ & $<0.001$ \\
\hline
\end{tabular}

Figure S2 Multivariate regression analyses of the independent effects of age on different metastasis sites. CI, confidence interval. 


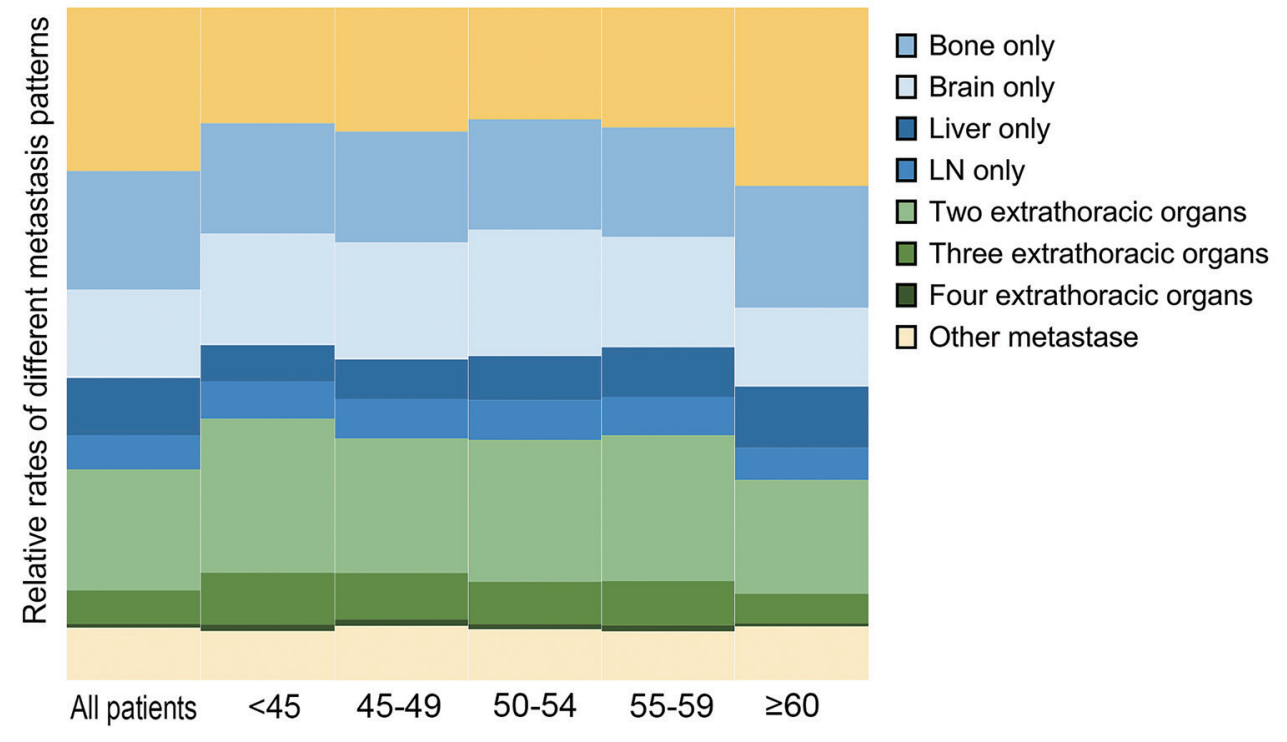

Figure S3 Relative rates of intrathoracic metastasis and single- and multi-extrathoracic organs in different age groups. LN, lymph node.

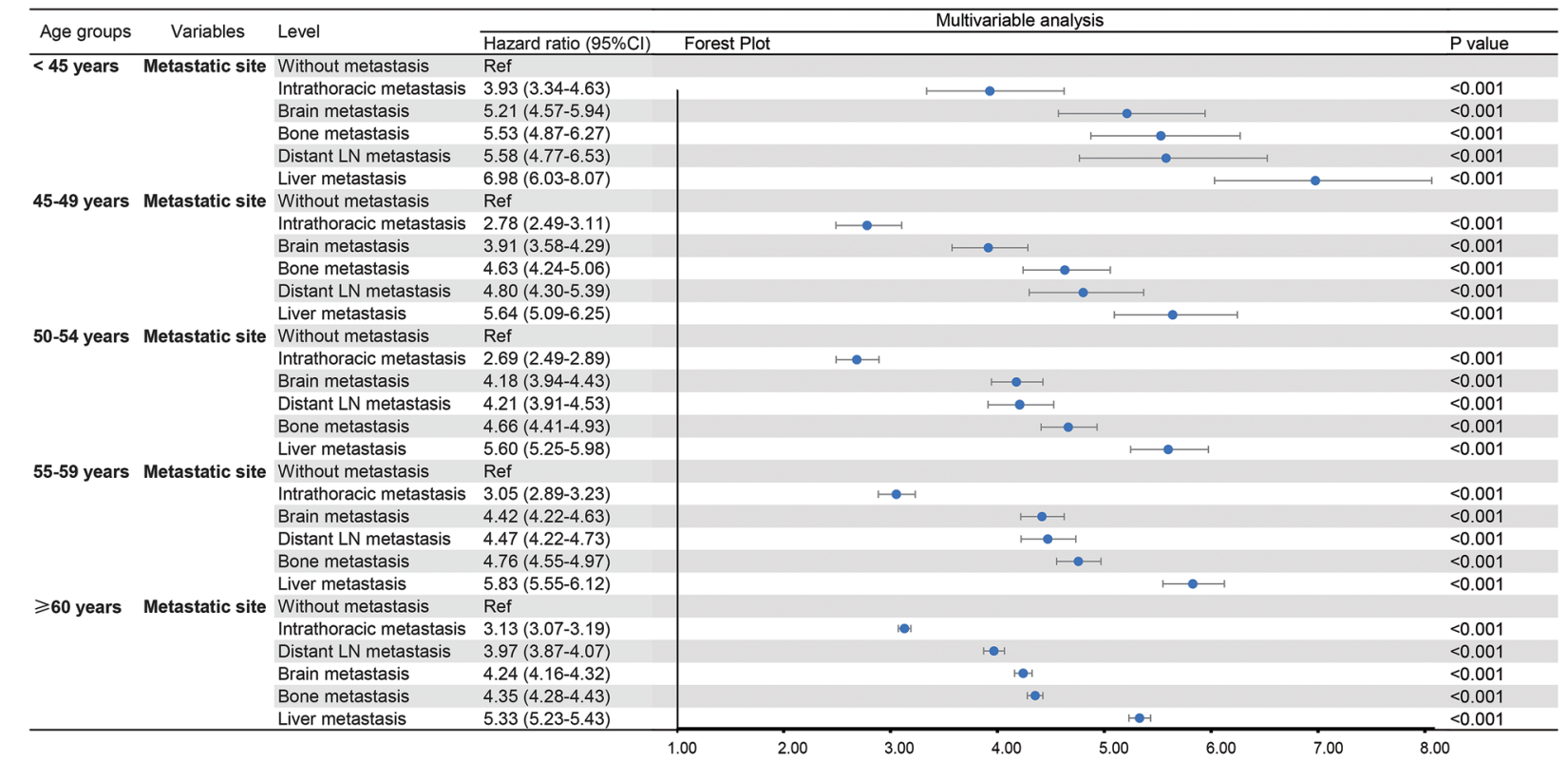

Figure S4 Multivariate analyses of the impact of age on LCSS for lung cancer patients. LCSS, lung cancer-specific survival; CI, confidence interval. 
A.

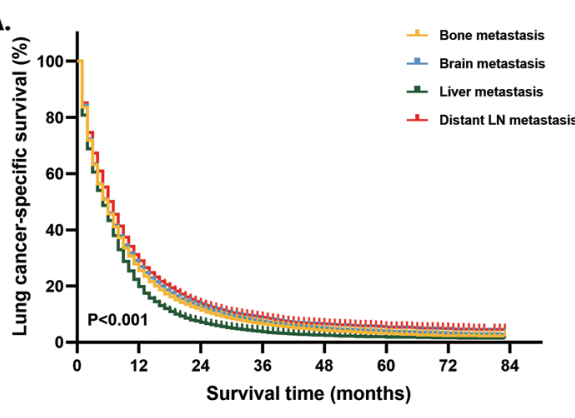

C.
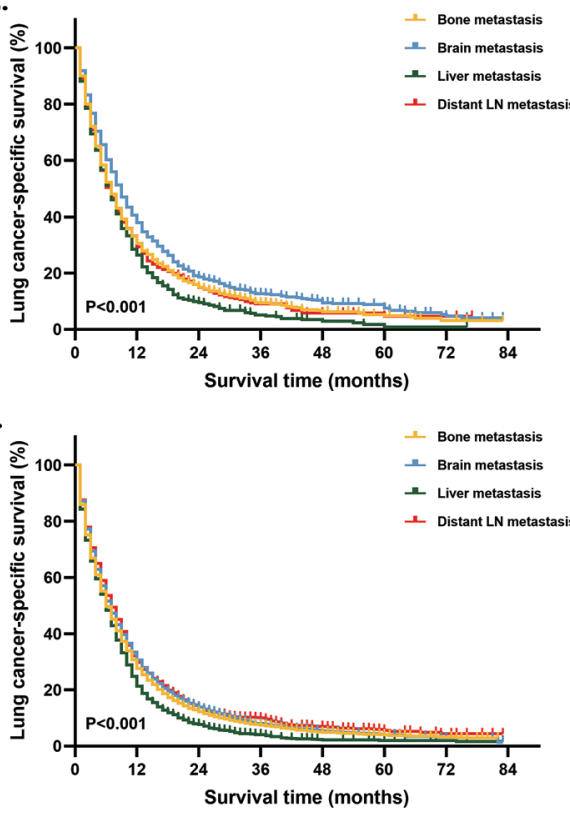

B.

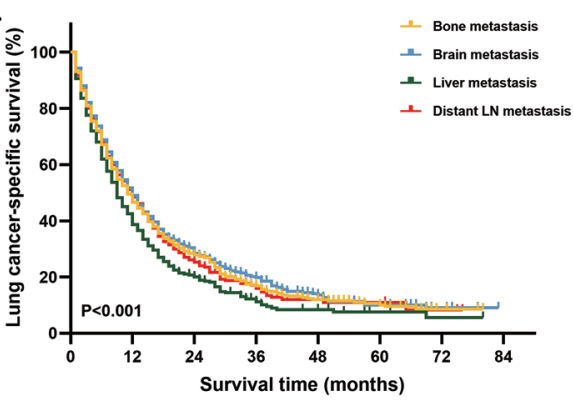

D.
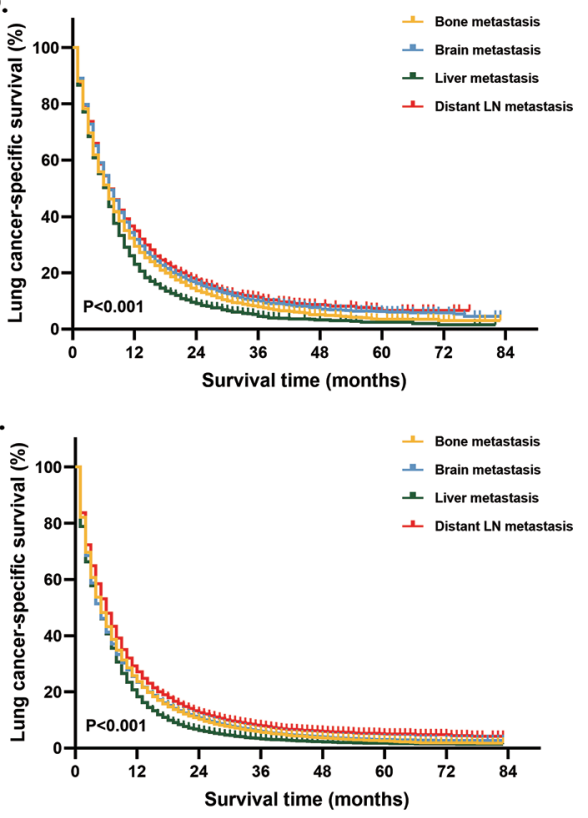

Figure S5 Kaplan-Meier LCSS curves for lung cancer patients at different ages stratified by extrathoracic metastasis organs. (A) All lung cancer patients; (B) patients aged <45 years; (C) patients aged 45-49 years; (D) patients aged 50-54 years; (E) patients aged 55-59 years; (F) patients $\geq 60$ years. LCSS, lung cancer-specific survival; LN, lymph node. 
Table S1 Relative rates of different metastatic patterns across age groups

\begin{tabular}{|c|c|c|c|c|c|c|}
\hline Metastasis site & $\begin{array}{l}<45 \text { years } \\
(n=3,461)\end{array}$ & $\begin{array}{l}45-49 \text { years } \\
(n=5,697)\end{array}$ & $\begin{array}{l}50-54 \text { years } \\
(n=13,645)\end{array}$ & $\begin{array}{l}\text { 55-59 years } \\
(n=22,211)\end{array}$ & $\begin{array}{l}\geq 60 \text { years } \\
(n=155,348)\end{array}$ & $P$ value \\
\hline Metastasis & $1,961(56.7)$ & $3,384(59.4)$ & $7,883(57.8)$ & $12,416(55.9)$ & $77,944(50.2)$ & $<0.001$ \\
\hline Intrathoracic metastasis & $338(9.8)$ & $621(10.9)$ & $1,311(9.6)$ & 2,205 (9.9) & $20,671(13.3)$ & $<0.001$ \\
\hline Extrathoracic metastasis & $1,481(42.8)$ & $2,487(43.7)$ & $5,973(43.8)$ & $9,288(41.8)$ & 51,045 (32.9) & $<0.001$ \\
\hline One site & $862(24.9)$ & $1,542(27.1)$ & 3,757 (27.5) & $5,663(25.5)$ & 34,055 (21.9) & $<0.001$ \\
\hline Bone only & $322(9.3)$ & $559(9.8)$ & $1,296(9.5)$ & $2,021(9.1)$ & $14,075(9.1)$ & 0.167 \\
\hline Brain only & $326(9.4)$ & $589(10.3)$ & $1,483(10.9)$ & 2,034 (9.2) & $9,138(5.9)$ & $<0.001$ \\
\hline Liver only & $104(3.0)$ & $195(3.4)$ & $516(3.8)$ & $903(4.1)$ & $7,067(4.5)$ & $<0.001$ \\
\hline Distant LN only & $110(3.2)$ & $199(3.5)$ & $462(3.4)$ & 705 (3.2) & $3,775(2.4)$ & $<0.001$ \\
\hline Two sites & $449(13.0)$ & $676(11.9)$ & $1,662(12.2)$ & $2,693(12.1)$ & $13,166(8.5)$ & $<0.001$ \\
\hline Bone + brain & $160(4.6)$ & $210(3.7)$ & $492(3.6)$ & $757(3.4)$ & $3,181(2.0)$ & $<0.001$ \\
\hline Bone + liver & $124(3.6)$ & $202(3.5)$ & $511(3.7)$ & $937(4.2)$ & $5,245(3.4)$ & $<0.001$ \\
\hline Bone + distant LN & $73(2.1)$ & $84(1.5)$ & $232(1.7)$ & 325 (1.5) & $1,577(1.0)$ & $<0.001$ \\
\hline Brain + liver & $33(1.0)$ & $73(1.3)$ & $173(1.3)$ & 287 (1.3) & 1,323 (0.9) & $<0.001$ \\
\hline Brain + distant LN & $36(1.0)$ & $68(1.2)$ & $159(1.2)$ & $225(1.0)$ & $910(0.6)$ & $<0.001$ \\
\hline Liver + distant LN & $23(0.7)$ & $39(0.7)$ & $95(0.7)$ & $162(0.7)$ & $930(0.6)$ & 0.127 \\
\hline Three sites & $151(4.4)$ & $235(4.1)$ & $493(3.6)$ & $821(3.7)$ & $3,444(2.2)$ & $<0.001$ \\
\hline Bone + brain + liver & $79(2.3)$ & $102(1.8)$ & $239(1.8)$ & $388(1.7)$ & $1,661(1.1)$ & $<0.001$ \\
\hline Bone + brain + distant LN & $23(0.7)$ & $53(0.9)$ & $99(0.7)$ & $170(0.8)$ & $497(0.3)$ & $<0.001$ \\
\hline Bone + liver + distant LN & $43(1.2)$ & $70(1.2)$ & $123(0.9)$ & $219(1.0)$ & $1,066(0.7)$ & $<0.001$ \\
\hline Brain + liver + distant LN & $6(0.2)$ & $10(0.2)$ & $32(0.2)$ & $44(0.2)$ & $220(0.1)$ & 0.037 \\
\hline Four sites & $19(0.5)$ & $34(0.6)$ & $61(0.4)$ & $111(0.5)$ & $380(0.2)$ & $<0.001$ \\
\hline
\end{tabular}

LN, lymph node. 


\begin{tabular}{|c|c|c|c|}
\hline Characteristics & $\mathrm{HR}$ & $95 \% \mathrm{Cls}$ & $P$ value \\
\hline Age & & & $<0.001$ \\
\hline$\geq 60$ years & Ref. & & \\
\hline $55-59$ years & 0.91 & $0.89-0.92$ & $<0.001$ \\
\hline $50-54$ years & 0.86 & $0.85-0.88$ & $<0.001$ \\
\hline $45-49$ years & 0.84 & $0.81-0.86$ & $<0.001$ \\
\hline$<45$ years & 0.67 & $0.64-0.70$ & $<0.001$ \\
\hline \multicolumn{4}{|l|}{ Sex } \\
\hline Male & Ref. & & \\
\hline Female & 0.81 & $0.80-0.82$ & $<0.001$ \\
\hline \multicolumn{4}{|l|}{ Race } \\
\hline White & Ref. & & \\
\hline Black & 0.98 & $0.97-1.00$ & 0.033 \\
\hline Other/unknown & 0.79 & $0.77-0.80$ & $<0.001$ \\
\hline Histology & & & $<0.001$ \\
\hline Adenocarcinoma & Ref. & & \\
\hline Squamous cell carcinoma & 1.24 & $1.22-1.26$ & $<0.001$ \\
\hline Large cell carcinoma & 1.35 & $1.29-1.40$ & $<0.001$ \\
\hline SCLC & 1.42 & $1.40-1.45$ & $<0.001$ \\
\hline Other NSCLC & 1.14 & $1.12-1.16$ & $<0.001$ \\
\hline Grade & & & $<0.001$ \\
\hline Unknown & Ref. & & \\
\hline Grade I-II & 0.78 & $0.77-0.79$ & $<0.001$ \\
\hline Grade III-IV & 1.11 & $1.10-1.13$ & $<0.001$ \\
\hline Primary site & & & $<0.001$ \\
\hline Main bronchus & Ref. & & \\
\hline Upper lobe, lung & 0.82 & $0.80-0.84$ & $<0.001$ \\
\hline Middle lobe, lung & 0.77 & $0.74-0.79$ & $<0.001$ \\
\hline Lower lobe, lung & 0.84 & $0.82-0.86$ & $<0.001$ \\
\hline Overlapping lesion of lung & 1.05 & $0.99-1.10$ & 0.082 \\
\hline Unknown & 0.96 & $0.94-0.99$ & 0.002 \\
\hline Surgery & & & $<0.001$ \\
\hline No & Ref. & & \\
\hline Yes & 0.24 & $0.24-0.25$ & $<0.001$ \\
\hline Radiation & & & $<0.001$ \\
\hline No & Ref. & & \\
\hline Yes & 0.82 & $0.81-0.82$ & $<0.001$ \\
\hline Chemotherapy & & & $<0.001$ \\
\hline No & Ref. & & \\
\hline Yes & 0.51 & $0.51-0.52$ & $<0.001$ \\
\hline Metastasis status & & & $<0.001$ \\
\hline No & Ref & & \\
\hline Yes & 2.46 & $2.43-2.49$ & $<0.001$ \\
\hline
\end{tabular}

OS, overall survival; HR, hazard ratio; $\mathrm{Cl}$, confidence interval; SCLC, small cell lung cancer; NSCLC, non-small cell lung cancer. 